\title{
Deficiency of complement component 5 ameliorates glaucoma in DBA/2J mice
}

\author{
Gareth R Howell ${ }^{1 *}$, lleana Soto ${ }^{1 \dagger}$, Margaret Ryan ${ }^{1}$, Leah C Graham ${ }^{1}$, Richard S Smith ${ }^{1}$ and Simon WM John ${ }^{1,2,3^{*}}$
}

\begin{abstract}
Background: Glaucoma is an age-related neurodegenerative disorder involving the loss of retinal ganglion cells (RGCs), which results in blindness. Studies in animal models have shown that activation of inflammatory processes occurs early in the disease. In particular, the complement cascade is activated very early in DBA/2J mice, a widely used mouse model of glaucoma. A comprehensive analysis of the role of the complement cascade in DBA/2J glaucoma has not been possible because DBA/2J mice are naturally deficient in complement component 5 ( $\mathrm{C} 5$, also known as hemolytic complement, $\mathrm{Hc}$ ), a key mediator of the downstream processes of the complement cascade, including the formation of the membrane attack complex.
\end{abstract}

Methods: To assess the role of C5 in DBA/2J glaucoma, we backcrossed a functional C5 gene from strain C57BL/6J to strain DBA/2J for at least 10 generations. The prevalence and severity of glaucoma was evaluated using ocular examinations, IOP measurements, and assessments of optic nerve damage and RGC degeneration. To understand how $\mathrm{C} 5$ affects glaucoma, C5 expression was assessed in the retinas and optic nerves of C5-sufficient DBA/2J mice, using immunofluorescence.

Results: C5-sufficient DBA/2J mice developed a more severe glaucoma at an earlier age than standard DBA/2J mice, which are therefore protected by C5 deficiency. Components of the membrane attack complex were found to be deposited at sites of axonal injury in the optic nerve head and associated with RGC soma in the retina.

Conclusion: C5 plays an important role in glaucoma, with its deficiency lessening disease severity. These results highlight the importance of fully understanding the role of the complement cascade in neurodegenerative diseases. Inhibiting C5 may be beneficial as a therapy for human glaucoma.

\section{Introduction}

Glaucoma, the second leading cause of blindness worldwide, is a neurodegenerative disease involving the death of retinal ganglion cells (RGCs) and degeneration of the optic nerve [1-3]. Major risk factors include aging and increased intraocular pressure (IOP). A number of processes have been implicated in glaucoma, but the key molecules that mediate early damage remain unclear. Upregulation and activation of complement proteins are consistent features of human glaucoma and animal models of glaucoma [4-7]. Despite the importance of the complement cascade, the exact roles of specific pathway members in glaucoma have not been determined.

\footnotetext{
* Correspondence: gareth.howell@jax.org; simon.john@jax.org

${ }^{\dagger}$ Equal contributors

${ }^{1}$ The Jackson Laboratory, 600 Main Street, Bar Harbor, Maine, ME, USA

Full list of author information is available at the end of the article
}

The complement cascade is activated as part of an innate immune response against pathogens. It also serves to clear unwanted cells and cellular debris [8], and has been shown to mediate synapse elimination in the central nervous system (CNS) [9]. Three major variants of the complement cascade have been widely studied: the classical, the alternative, and the lectin pathways. A major effector molecule of all three pathways is complement component C5 [10]. The C5 protein is cleaved by C5 convertases to produce C5a and C5b peptides. C5a is an anaphylotoxin that can mediate neuroinflammatory responses, while $\mathrm{C} 5 \mathrm{~b}$ is a key molecule in the formation of the membrane attack complex (MAC). The MAC is a transmembrane channel composed of the complement factors C5b, C6, C7, C8, and C9 (C5b-9) and is formed in the cell membrane of target cells, causing lysis [11].

DBA/2J mice are widely used as a model of inherited glaucoma. DBA/2J mice develop hallmarks of human

\section{Biomed Central}


glaucoma including an age-related increase in IOP, and an early insult to RGC axons at the optic nerve head [12-14]. As in humans, lowering IOP lessens or prevents glaucoma in DBA/2J mice [15-17]. Previous studies have shown that activation of the complement cascade occurs in both the retina and the optic nerve head in DBA/2J glaucoma $[4,18,19]$. Hierarchical clustering of gene expression data predicts that activation of the complement cascade is an early event in DBA/2J glaucoma [4]. Highlighting the importance of the complement cascade, DBA/2J mice mutant for the complement component C1qa gene, an initiating factor in the classical pathway, show a significant reduction in glaucomatous RGC loss and optic nerve degeneration compared with normal DBA/2J mice [4].

C5 is reported to play both beneficial and damaging roles in neurodegenerative diseases including Alzheimer's disease [20-22] and Huntington's disease [23]. C5 deficiency also delays Wallerian degeneration and inhibits monocyte recruitment after peripheral nerve injury [24]. Therefore, C5 would be predicted to affect glaucoma, but functional experiments to determine its specific role in glaucoma have not been performed. Contributing to the lack of study of C5 in glaucoma is the fact that DBA/2J mice are naturally deficient in C5 $[25,26]$. Thus, to determine the effects of C5 in glaucoma, we developed C5-sufficient DBA/2J mice by transferring a functional $C 5$ gene from strain C57BL/6J. C5-sufficient DBA/2J mice develop a more severe form of glaucoma than C5-deficient DBA/ 2J mice indicating an important role for $\mathrm{C} 5$ in glaucoma.

\section{Methods}

Mouse strains, breeding, and husbandry

All experiments were performed in compliance with the ARVO statement for use of animals in ophthalmic and vision research. All experiments involving animals were approved by The Jackson Laboratory Animal Care and Use Committee. All mice were bred at the Jackson Laboratory and housed with a 14-hour-light/10-hour-dark cycle, under the same conditions as previously described [27]. To generate C5-sufficient DBA/2J mice (herein referred to as DBA/ 2J.C5 ${ }^{B 6}$, official strain name DBA/2J.B6- $H c^{+} / \mathrm{Sj}$ ), the interval of mouse chromosome 2 containing a functional $C 5$ gene was backcrossed to DBA/2J for 11 generations. Mice heterozygous for the B6 region containing $C 5$ were intercrossed to generate cohorts of DBA/2J mice of all $C 5$ genotypes $\left(C 5^{D 2 / D 2}, C 5^{D 2 / B 6}\right.$ and $\left.C 5^{B 6 / B 6}\right)$. There were no observable differences between $C 5^{D 2 / B 6}$ and $C 5^{B 6 / B 6}$ mice, thus unless otherwise stated, these are collectively referred to as $C 5^{B 6}$.

\section{Determining the congenic interval in $\mathrm{D} 2 . \mathrm{C5}^{\mathrm{B6}}$ mice}

The extent of the B6-derived region was analyzed after 11 generations of backcrossing using polymorphic markers spanning the proximal portion of mouse chromosome 2 (identified using Ensembl and Mouse Genome Informatics). Polymorphic markers included D2Mit296 (D2 = 144 bp, B6 = 154 bp), D2Mit367 (D2 = 162 bp, B6 = 149 bp), D2Mit369 (D2 = 110 bp, B6 = 129 bp), D2Mit241 (D2 = $96 \mathrm{bp}, \mathrm{B} 6=135 \mathrm{bp}$ ) and D2Mit376 (D2 = 86 bp, B6 = 92 bp). For each marker, DNA was amplified by PCR from D2. $5^{B 6}, \mathrm{D} 2$, and B6 mice under standard conditions. Products were resolved in $3 \%$ agarose gels.

\section{Iris disease and IOP measurement}

In standard DBA/2J mice, glaucomatous IOP elevation follows the onset of the iris disease [28]. Therefore, when altering the genotype of DBA/2J mice, it is necessary to evaluate both iris disease and IOP elevation. Iris disease was followed in mice using a slit-lamp biomicroscope as previously reported [29]. IOP measurements were performed using the microneedle method as previously described [30]. Ages and sample sizes are detailed in the results and figure legends. Statistical analysis was performed using ANOVA (JMP statistical package).

\section{Tissue harvesting and processing}

Eyes, with the intra-orbital portion of the optic nerve still attached, were enucleated and fixed overnight in 4\% paraformaldehyde (PFA) at $4^{\circ} \mathrm{C}$. The retro-orbital portions of the optic nerve (to the chiasm) were carefully removed from the underside of the brain and fixed in 4\% PFA overnight. Eyes and optic nerves were stored in $0.5 \mathrm{~mol} / \mathrm{L}$ phosphate buffer at $4^{\circ} \mathrm{C}$.

\section{Immunofluorescence and RGC quantification}

For immunofluorescence, whole retinas were dissected free, washed with 1X PBS-T (phosphate-buffered saline with $0.5 \%$ Triton-X100), and incubated with monoclonal antibodies against tubulin $\beta$-III (TUBB3; 1:500; SigmaAldrich, St Louis, MO, USA) and rabbit polyclonal C5b9 (1:200; Calbiochem, San Diego, CA, USA) for 96 hours at $4{ }^{\circ} \mathrm{C}$. After washing 3 times with PBS-T, the retinas were incubated in the respective secondary antibodies for 2 hours. The retinas were further washed in PBS-T and mounted (Aqua Poly/Mount; Polysciences, Warrington, PA, USA), and imaging was performed (Axio Imager; Zeiss, Jena, Germany). For quantification of TUBB3immunolabeled RGCs, cuts were made in the retinas to divide it into four equal quadrants, and two digital images $(350 \times 350 \mu \mathrm{m})$ were taken of the peripheral retina in each quadrant. Manual counts were performed using the cell count tool from the Fiji software (http://imagej.nih.gov/ij). The number of retinas per group is given in the Results section and figure legends.

For immunofluorescence of the intra-orbital portion of the optic nerve and optic nerve head, eyes with the 
intra-orbital nerve still attached were immersed in 30\% sucrose (until they sank), rinsed in $1 \times$ PBS and frozen in optical cutting temperature (OCT) compound. Eyes were cut into $10 \mu \mathrm{m}$ sections, and the central sections containing optic nerve were stained with polyclonal C5b-9 and monoclonal phosphorylated neurofilament (pNF; 1:500, Dako, Glostrop, Denmark) as described previously [4]. For each experiment, at least four sections from six eyes for each glaucoma severity for each genotype were assessed. Imaging and photography was performed on both an imaging microscope (Axio Imager; Zeiss) microscope and a confocal microscope (SP5; Leica, Heerbrugg, Switzerland).

\section{Assessment of glaucomatous damage}

Retro-orbital optic nerves (within 1 to $2 \mathrm{~mm}$ of the orbit) were processed for plastic sectioning and para- phenylenediamine (PPD) staining to differentiate severity of glaucoma, and analyzed as previously reported $[28,31]$. Eyes had one of three damage levels: no or early (NOE, $<10 \%$ axons damaged/lost), moderate $(<50 \%$ axons damaged/lost) or severe (>50\% axons damaged/ lost).

\section{Results}

D2.C $5^{\mathrm{B} 6}$ mice develop a disease of the iris and a glaucomatous IOP profile

DBA/2J (D2) mice do not express a functional C5 protein, owing to a frameshift mutation in the C5 gene [26]. To determine the affect of a functioning C5 gene on the progression of D2 glaucoma, the C5 allele from $\mathrm{C} 57 \mathrm{BL} / 6 \mathrm{~J}$ (B6) mice was backcrossed into the DBA/2J strain (D2.C $5^{\mathrm{B} 6}$ ) (Figure 1A). D2 mice develop a secondary glaucoma as a result of an iris disease,

A

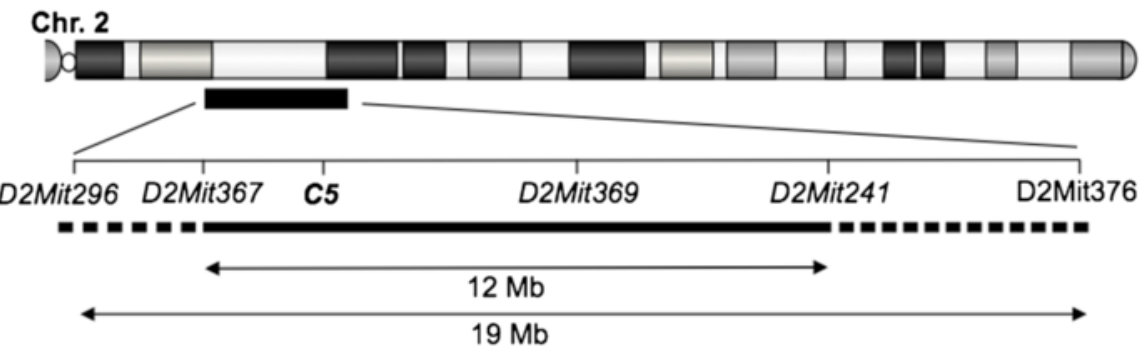

B

D2
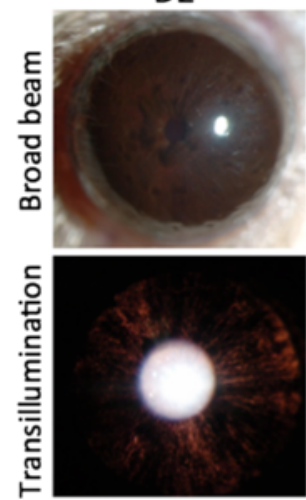

8.5 months
D2.C5 $5^{86}$
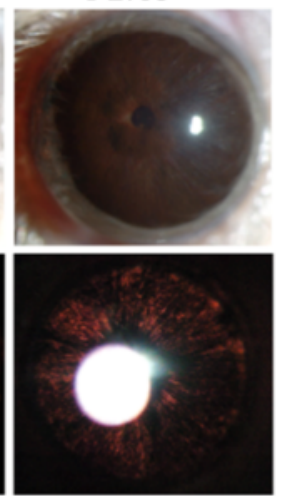

Age (mos) 4.0

C

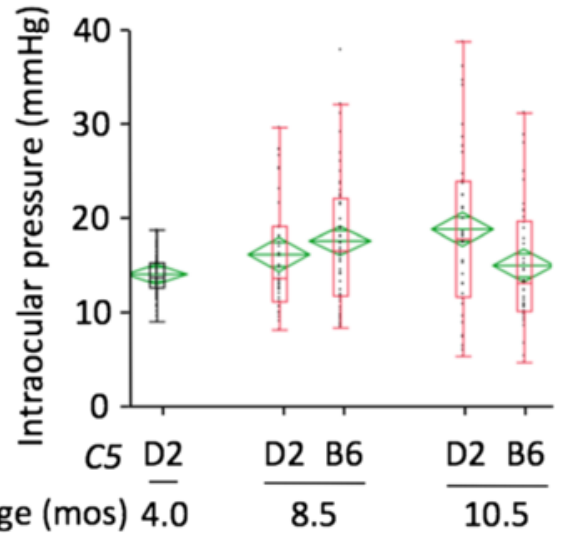

Figure 1 Progression of iris disease and intraocular pressure (IOP) profiles in DBA/2J and D2.C5 ${ }^{B 6}$ mice. (A) The congenic interval surrounding $C 5$ in D2.C5 $5^{B 6}$ mice determined using markers polymorphic between D2 and B6 (see Methods). The proximal and distal breakpoints are indicated by the dotted line. The confirmed congenic interval from B6 is shown as a solid line. The size of the congenic interval is between $12 \mathrm{Mb}$ and $19 \mathrm{Mb}$, which equates to less than $0.5 \%$ of the mouse genome. Analysis of known variations between D2 and B6 showed that C5 is the only gene in this region that has a null mutation in D2 compared with B6. (B) Eye examinations with broad-beam illumination (top) and transillumination (bottom) found no obvious differences in iris disease progression between D2.C5 ${ }^{B 6}$ and DBA/2J mice. (C) Age-dependent elevation of IOP was found in both D2 and D2.C5 ${ }^{B 6}$ mice (red) compared with young D2 mice (black). Box plots were generated using JMP version 7.0. The ends of each box represent the 75th and 25th percentile. The lines across the middle of each box indicate the median value. The whiskers extending from either end indicate the extent of the data points. Values falling outside the whiskers are considered outliers. The green diamonds indicate the mean and the $95 \%$ confidence interval. 

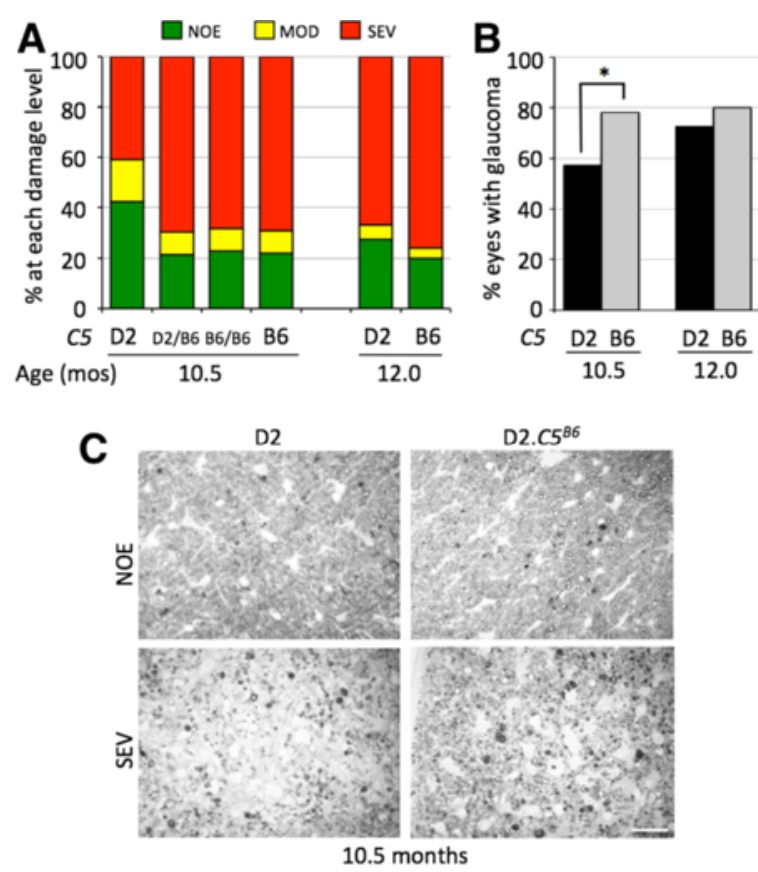

Figure 2 Glaucomatous neurodegeneration was more severe in D2.C5 ${ }^{B 6}$ mice. (A) Distributions of optic nerve damage showed a significant increase in the number of eyes with moderate (MOD; $<50 \%$ axons damaged/lost) and severe (SEV; $>50 \%$ axons damaged/lost) glaucoma at 10.5 months in D2.C5 $5^{B 6}$ compared with normal D2 mice $(P=0.0001)$. There was no difference between D2 mice carrying one (D2.C5 $\left.{ }^{D 2 / B 6}\right)$ or two functioning copies $\left(D 2 . C 5^{B 6 / B 6}\right)$ of the $C 5$ gene. Number of eyes: 10.5 months; $D 2=54, D 2 . C 5^{D 2 / B 6}=33, D 2 . C 5^{B 6 / B 6}=22$, D2.C5 ${ }^{B 6}$ (Combined D2. $C 5^{D 2 / B 6}$ and $\left.D 2 . C 5^{B / B 6}\right)=55.12$ months; $\mathrm{D} 2=33, \mathrm{~B} 6$ (combined) $=25$. NOE, no or early glaucoma (no detectable axon loss but some eyes may have early molecular changes). (B) A summary of the optic nerve damage assessment shown in (A). At 10.5 months of age, $78 \%$ of eyes from D2. $C 5^{B 6}$ mice showed either MOD or SEV glaucoma compared with only 57\% of D2 mice. C) Examples of NOE and SEV damaged nerves in D2 and D2.C5 $5^{B 6}$. Scale bar $=25 \mu \mathrm{m}$.

followed by IOP elevation. To determine whether a functioning C5 gene had an effect on the iris disease, detailed ocular examinations were performed on at least $20 \mathrm{D} 2$ and $20 \mathrm{D} 2 . C 5^{B 6}$ mice at $6,8,10$, and 12 months of age. Both D2 and D2.C5 ${ }^{B 6}$ mice developed the characteristic iris disease (Figure 1B). No obvious differences in the onset or progression of iris stromal atrophy (ISA) or iris pigment dispersion (IPD) were seen between D2 and D2. $C 5^{B 6}$ mice (Figure 1B).

We next compared IOP levels between D2.C5 ${ }^{B 6}$ and D2 mice (Figure 1C). In D2 mice, IOP first started to increase in a significant number of eyes at 8 to 8.5 months
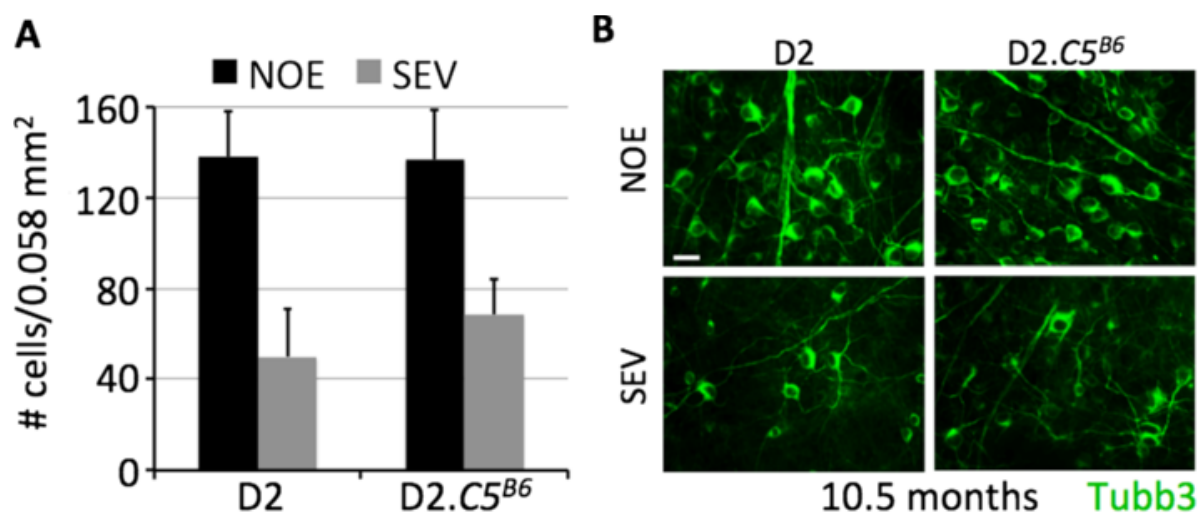

Figure 3 Significant loss of retinal ganglion cells (RGCs) in both D2 and D2.C5 ${ }^{\text {B6 }}$ mice. (A) Tubulin $\beta$-III (TUBB3)-labeled RGCS were counted in flat-mount retinas with no or early (NOE) or severe (SEV) glaucoma at 10.5 months of age for both DBA/2J and D2.C5 ${ }^{B 6}$ mice. RGC degeneration matched the severity of optic-nerve degeneration in both groups. Eight retinas of each age/genotype were counted. (B) Example images of TUBB3-labeled RGCS in flat-mount retinas with NOE and SEV glaucomatous damage in D2 and D2.C5 ${ }^{B 6}$. Scale bar $=20 \mu \mathrm{m}$. 
of age and was increased in many eyes at 10.5 months of age [31]. Therefore, IOP levels were measured at these key ages. For both D2.C5 ${ }^{B 6}$ and D2 mice, IOP levels were higher than those in young D2 controls. There was no significant difference between the IOP profiles of D2. $C 5^{B 6}$ and D2 mice at 8.5 months of age $(P=0.23)$, suggesting that C5 sufficiency does not affect the onset of IOP increase. However, at 10.5 months of age, IOP levels were significantly lower in D2.C5 $5^{B 6}$ mice compared with D2 mice $(P=0.003)$. This difference suggests that, although $D 2 . C 5^{B 6}$ mice had a glaucomatous IOP profile (as judged by a significant elevation in IOP levels in D2.C5 $5^{B 6}$ mice at $8.5(P=0.002)$ and 10.5 months of age $(P<0.0001)$ compared with $\mathrm{DBA} / 2 \mathrm{~J}$ control mice at 4.0 months), C5 sufficiency may affect the extent of IOP elevation in D2.C5 $5^{B 6}$ mice.
More D2.C5 $5^{\mathrm{B} 6}$ mice develop severe glaucoma at an earlier age than D2 mice

In our colony, glaucomatous optic nerve degeneration in D2 mice is typically observed between 10 and 12 months of age $[1,31]$. D2.C $5^{B 6}$ mice showed a significant increase in the number of eyes with severe glaucoma at 10.5 months of age (69\%) compared with normal D2 eyes (38\%, $P=0.0001$ ) (Figure 2). At 12 months of age, the number of D2.C5 ${ }^{B 6}$ eyes with severe glaucoma was not significantly different to normal D2 eyes of the same age (76\% compared with $67 \%, P=0.09$ ).

Previous studies have separated RGC axon degeneration in the optic nerve from the death of RGC somas. For instance, in D2 mice that are deficient for the proapoptotic gene $B A X$, optic nerves degenerate to the same extent as in normal BAX-sufficient D2 mice, but
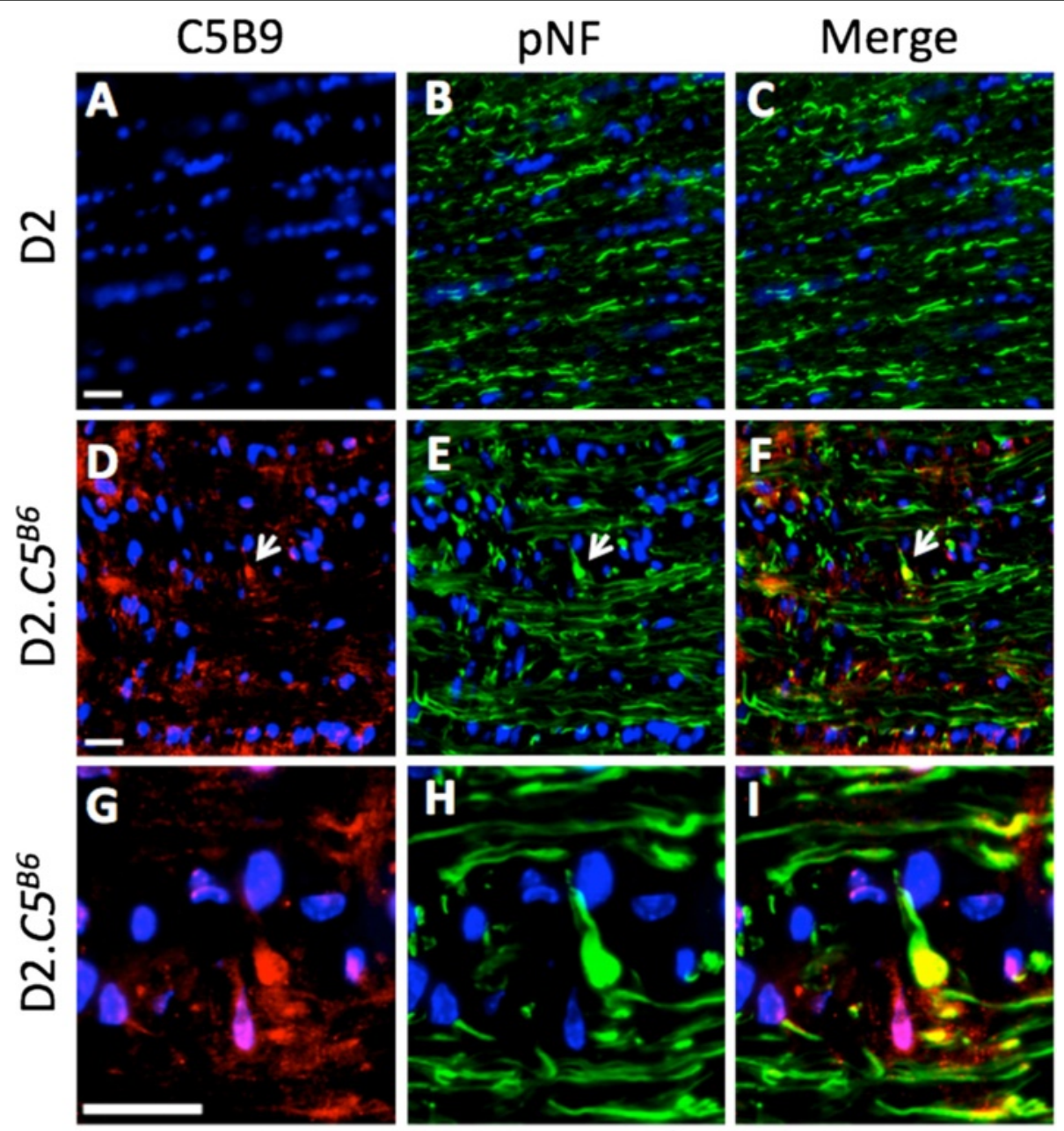

NOE 8 months

Figure 4 Membrane attack complex (MAC) deposition in dystrophic axons during early glaucoma in D2.C5 ${ }^{B 6}$ optic nerves. (A-C) As expected, no MAC deposition was seen in D2 optic nerve axons at 10.5 months of age. (D-F) However, MAC deposition (as judged by the presence of anti-C5b-9) was found in the optic nerve head from D2.C5 $5^{B 6}$ mice with no or early (NOE) glaucoma. (G-I) High magnification views from D-F, showing some dystrophic neurites were labeled by anti-C5b-9, indicating deposition of MAC in these degenerative structures (arrows). Scale bar $=20 \mu \mathrm{m}$. 
RGC soma survive [32]. Therefore, to determine the extent of $\mathrm{RGC}$ somal loss in D2.C5 $5^{B 6}$ mice, retinal flat mounts from D2.C5 ${ }^{B 6}$ and D2 eyes with no detectable glaucoma (NOE) and severe glaucoma were labeled with TUBB3, and the TUBB3-positive cells in the ganglion cell layer were counted (see Methods). Both D2.C5 $5^{B 6}$ and D2 eyes with severe glaucoma showed significant loss of RGCs (Figure 3). Collectively, our data showed that a functional $C 5$ gene significantly exacerbates both optic-nerve degeneration and RGC somal loss in DBA/ 2J mice.

\section{MAC deposition on RGC axons and soma very early in glaucoma}

C5 has been shown to play multiple roles in neurodegenerative diseases and after neuronal injury [21,23,33-35]. The C5 protein is cleaved by C5 convertases to produce $\mathrm{C} 5 \mathrm{a}$ and $\mathrm{C} 5 \mathrm{~b}$. C5a plays an important role in inflammation, while $\mathrm{C} 5 \mathrm{~b}$ is involved in cell lysis [10]. To begin to determine how a functioning $\mathrm{C} 5$ protein may contribute to more severe glaucoma in D2.C5 $5^{B 6}$ mice, optic nerves were analyzed with anti-C5b-9, an antibody that recognizes a functioning MAC. In D2.C5 ${ }^{B 6}$ eyes with early glaucoma but no detectable axon loss, MAC deposition was found in RGC axonal swellings (or dystrophic neurites) in the optic nerve (Figure 4). Dystrophic neurites are an early sign of RGC axon damage in the optic nerve head in glaucoma [12]. As expected, C5b-9 was not seen in C5deficient D2 mice (Figure 4A-C).

Previous work has also shown that the MAC can be deposited on neuronal bodies after injury [20,21,23]. Therefore, to determine whether a functioning $C 5$ gene results in MAC deposition in RGC soma in glaucoma, we localized C5b-9 in retinas from D2.C5 ${ }^{B 6}$ eyes with early glaucoma. To identify RGCs, retinas were colabeled with anti-TUBB3 antibody. Interestingly, in D2. $C 5^{B 6}$ eyes with no detectable optic nerve damage behind the eye, RGCs showed significant levels of MAC deposition (Figure 5). Again, no MAC staining was found in glaucomatous retinas from C5-deficient D2 mice. Together, these experiments support a role for $C 5$ and the MAC in the early stages of glaucomatous RGC loss in glaucoma.

\section{Discussion}

Previous work has shown increased expression of components of the classical complement pathway in glaucoma $[1,4-7,36]$. Glaucomatous neurodegeneration was reduced in $\mathrm{C} 1 \mathrm{qa}$-deficient $\mathrm{DBA} / 2 \mathrm{~J}$ mice, indicating a crucial role of this protein and the complement cascade in general in glaucoma [4]. It is thought that the expression of C1qa in either RGCs and/or microglia/monocytes mediates the glaucomatous damage to RGCs, although C1qa has also been reported to be expressed in other retinal cell types such as photoreceptors [37]. In this study, we show for the first time that a second key component of the complement cascade, C5, modulates the progression of RGC loss in DBA/2J glaucoma. Our results show that $\mathrm{C} 5$ deficiency protects normal D2 mice from glaucoma, with $\mathrm{C} 5$ sufficiency rendering mice prone to develop a more severe form of glaucoma.

Similar to other complement proteins, C5 is present in multiple locations and cell types during glaucoma, including the retina and the optic nerve head, and it could
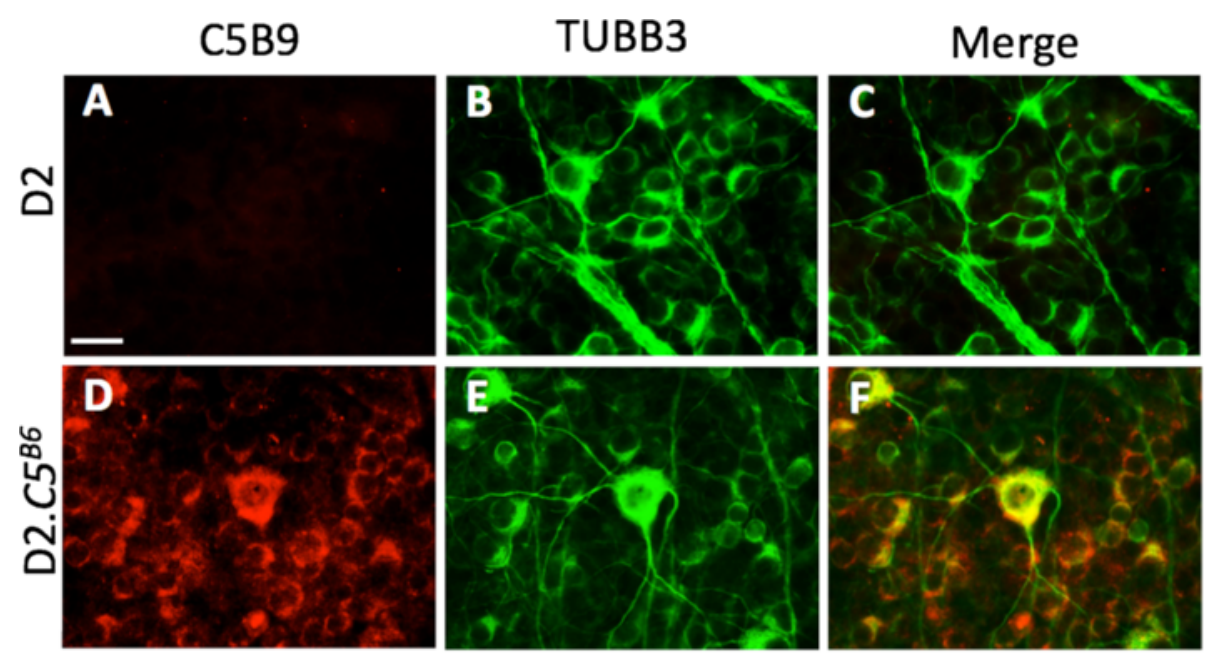

NOE 10.5 months

Figure 5 Membrane attack complex (MAC) deposition in retinal ganglion cell (RGC) soma in D2.C5 $5^{B 6}$ mice. (A-C) D2 retinas did not show any MAC staining. (D-F) Significant deposition of MAC was evident in RGCs from 10.5-month-old D2.C5 ${ }^{B 6}$ eyes with no or early (NOE) glaucoma. Scale bar $=20 \mu \mathrm{m}$. 
contribute to glaucoma in multiple ways including modulation of IOP elevation. For instance, C1qa and C3 have been shown to be necessary for synaptic pruning in the retina during development, and may be necessary for RGC synapse remodeling early in glaucoma [9]. C1qa may also mediate ribbon synapse remodeling in photoreceptors in DBA/2J mice [37], although we have not found any photoreceptor changes in our DBA/2J colony [31]. Further work is needed to determine the exact role (s) of C5 in synapse remodeling and other crucial processes in glaucoma.

The C5 protein can be converted into two active peptides, $\mathrm{C} 5 \mathrm{a}$, a proinflammatory anaphylatoxin, and $\mathrm{C} 5 \mathrm{~b}$, a key component in the formation of the MAC [10]. Therefore, a functioning C5 gene may provoke either a proinflammatory effect, the formation of the MAC, or both. C5a is a potent proinflammatory molecule involved in immune-cell recruitment and entry of cells into tissues from the vasculature [38-40], two events we have shown to be important in early stages of glaucoma [41]. It has also been shown that C5a can act directly on neurons through the C5a receptor $(C 5 a R)[42,43]$. Previous studies have reported that $\mathrm{C} 5 \mathrm{a}$ can exert a protective effect on neurons expressing C5aR after neuronal excitotoxicity $[42,44]$. Interestingly, in our microarray studies, C5aR was increased in the early stages of glaucoma in both the retina and the optic nerve head $[4,45]$. However, the C5-sufficient D2 mice were more prone to severe glaucoma compared with the C5-deficient DBA/2J mice, implying either a different role for $\mathrm{C} 5 \mathrm{a} / \mathrm{C} 5 \mathrm{aR}$, or a greater, more damaging, contribution from $\mathrm{C} 5 \mathrm{~b}$.

Generation of C5b is a necessary step in the formation of the MAC. We found significant MAC deposition in glaucomatous RGCs, and dystrophic neurites in optic nerves of D2.C5 ${ }^{B 6}$ mice. MAC deposition in RGCs has also been reported in human glaucoma and in other experimental models $[5,46]$. Studies have also identified significant MAC deposition in other neurodegenerative diseases such as traumatic brain injury (TBI) [34,47], acute brain ischemia [35], peripheral nerve injury [48], Alzheimer's disease [20-22,49], and Huntington's disease [23]. Our study suggests that MAC deposition may be a damaging event in glaucoma. This is also supported by studies that show that an increase in MAC deposition (using mice deficient for the MAC inhibitor CD59a) can have adverse neuropathological outcomes in experimental models of TBI [47], peripheral nerve injury [50], and tau pathology [51]. Therefore, although we cannot exclude a contribution of $\mathrm{C} 5 \mathrm{a}$, it is likely that MAC deposition is a major contributor to the increase in glaucoma severity in D2.C5 ${ }^{B 6}$ mice. Further work using specific ablation of either $\mathrm{C} 5 \mathrm{a}$ or $\mathrm{C} 5 \mathrm{~b}$ in specific cell types is needed to confirm this.

In summary, we have demonstrated that the downstream components of the complement cascade have a damaging role in glaucoma, and that the natural C5 deficiency protects D2 mice from severe glaucoma. This implies that a functional C5 protein affects RGC loss in human glaucoma, and that inhibition of C5 may be a useful target for treatment. Given that most humans have a functional C5 gene, C5-sufficient D2 mice may more closely model human glaucoma, and D2.C5 $5^{B 6}$ mice are therefore an important new strain for understanding the role of the complement cascade in glaucoma.

\section{Competing interests}

The authors of this manuscript have no competing interests.

\section{Authors' contributions}

GRH and SWMJ conceived and designed the study, and oversaw all experiments. ISR performed the immunofluorescence experiments and soma counts. MR generated the D2.C $5^{B 6}$ mouse strains, bred the mice, and harvested tissue for characterization. LG determined the congenic interval in the D2.C5 $5^{B 6}$ strain. RSS performed the characterization of the optic nerves for glaucomatous damage. ISR and GRH wrote the paper, with contributions from SWMJ. All authors have read and approved the final version of the manuscript.

\section{Acknowledgements}

We thank Stephen Kneeland for clinical examinations and Amy Bell for intraocular pressure measurements. This work was supported by $\mathrm{NIH}$ EY021525 (GRH) and NIH EY011721 (SWMJ). We are also grateful for the support from The Pew Charitable Trust, and the Barbara and Joseph Cohen Foundation. SWMJ is an Investigator of the Howard Hughes Medical Institute.

\section{Author details}

${ }^{1}$ The Jackson Laboratory, 600 Main Street, Bar Harbor, Maine, ME, USA. ${ }^{2}$ Howard Hughes Medical Institute, 600 Main Street, Bar Harbor, ME, USA. ${ }^{3}$ Department of Ophthalmology, Tufts University School of Medicine, Boston, MA, USA.

Received: 3 May 2013 Accepted: 12 June 2013

Published: 27 June 2013

\section{References}

1. Nickells RW, Howell GR, Soto I, John SW: Under pressure: cellular and molecular responses during glaucoma, a common neurodegeneration with axonopathy. Annu Rev Neurosci 2012, 35:153-179.

2. Burgoyne CF: A biomechanical paradigm for axonal insult within the optic nerve head in aging and glaucoma. Exp Eye Res 2011, 93(2):120-132.

3. Quigley HA: Glaucoma. Lancet 2011, 377(9774):1367-1377.

4. Howell GR, Macalinao DG, Sousa GL, Walden M, Soto I, Kneeland SC, Barbay JM, King BL, Marchant JK, Hibbs M, et al: Molecular clustering identifies complement and endothelin induction as early events in a mouse model of glaucoma. J Clin Invest 2011, 121(4):1429-1444.

5. Jha P, Banda H, Tytarenko R, Bora PS, Bora NS: Complement mediated apoptosis leads to the loss of retinal ganglion cells in animal model of glaucoma. Mol Immunol 2011, 48(15-16):2151-2158.

6. Rosen AM, Stevens B: The role of the classical complement cascade in synapse loss during development and glaucoma. Adv Exp Med Biol 2010, 703:75-93.

7. Ren L, Danias J: A role for complement in glaucoma? Adv Exp Med Biol 2010, 703:95-104.

8. Zipfel PF: Complement and immune defense: from innate immunity to human diseases. Immunol Lett 2009, 126(1-2):1-7.

9. Stevens B, Allen NJ, Vazquez LE, Howell GR, Christopherson KS, Nouri N, Micheva KD, Mehalow AK, Huberman AD, Stafford B, et al: The classical complement cascade mediates CNS synapse elimination. Cell 2007, 131(6):1164-1178.

10. Morgan BP: Regulation of the complement membrane attack pathway. Crit Rev Immunol 1999, 19(3):173-198.

11. Nauta AJ, Roos A, Daha MR: A regulatory role for complement in innate immunity and autoimmunity. Int Arch Allergy Immunol 2004, 134(4):310-323. 
12. Howell GR, Libby RT, Jakobs TC, Smith RS, Phalan FC, Barter JW, Barbay JM, Marchant JK, Mahesh N, Porciatti V, et al: Axons of retinal ganglion cells are insulted in the optic nerve early in DBA/2J glaucoma. J Cell Biol 2007, 179(7):1523-1537.

13. Schlamp CL, Li Y, Dietz JA, Janssen KT, Nickells RW: Progressive ganglion cell loss and optic nerve degeneration in DBA/2J mice is variable and asymmetric. BMC Neurosci 2006, 7:66.

14. Soto I, Oglesby E, Buckingham BP, Son JL, Roberson ED, Steele MR, Inman DM, Vetter ML, Horner PJ, Marsh-Armstrong N: Retinal ganglion cells downregulate gene expression and lose their axons within the optic nerve head in a mouse glaucoma model. J Neurosci 2008, 28(2):548-561.

15. Matsubara A, Nakazawa T, Husain D, lliaki E, Connolly E, Michaud NA, Gragoudas ES, Miller JW: Investigating the effect of ciliary body photodynamic therapy in a glaucoma mouse model. Invest Ophthalmol Vis Sci 2006, 47(6):2498-2507.

16. Schuettauf F, Quinto K, Naskar R, Zurakowski D: Effects of anti-glaucoma medications on ganglion cell survival: the DBA/2J mouse model. Vision Res 2002, 42(20):2333-2337.

17. Wong AA, Brown RE: A neurobehavioral analysis of the prevention of visual impairment in the DBA/2J mouse model of glaucoma. Invest Ophthalmol Vis Sci 2012, 53(9):5956-5966.

18. Panagis L, Zhao X, Ge Y, Ren L, Mittag TW, Danias J: Retinal gene expression changes related to IOP exposure and axonal loss in DBA/2J mice. Invest Ophthalmol Vis Sci 2011, 52(11):7807-7816.

19. Steele MR, Inman DM, Calkins DJ, Horner PJ, Vetter ML: Microarray analysis of retinal gene expression in the DBA/2J model of glaucoma. Invest Ophthalmol Vis Sci 2006, 47(3):977-985.

20. Itagaki S, Akiyama H, Saito H, McGeer PL: Ultrastructural localization of complement membrane attack complex (MAC)-like immunoreactivity in brains of patients with Alzheimer's disease. Brain Res 1994, 645(1-2):78-84.

21. McGeer PL, Akiyama H, Itagaki S, McGeer EG: Activation of the classical complement pathway in brain tissue of Alzheimer patients. Neurosci Lett 1989, 107(1-3):341-346.

22. Webster $\mathrm{S}$, Lue LF, Brachova L, Tenner AJ, McGeer PL, Terai K, Walker DG, Bradt B, Cooper NR, Rogers J: Molecular and cellular characterization of the membrane attack complex, C5b-9, in Alzheimer's disease. Neurobiol Aging 1997, 18(4):415-421.

23. Singhrao SK, Neal JW, Morgan BP, Gasque P: Increased complement biosynthesis by microglia and complement activation on neurons in Huntington's disease. Exp Neurol 1999, 159(2):362-376.

24. Liu L, Lioudyno M, Tao R, Eriksson P, Svensson M, Aldskogius H: Hereditary absence of complement $\mathrm{C} 5$ in adult mice influences Wallerian degeneration, but not retrograde responses, following injury to peripheral nerve. J Peripher Nerv Syst 1999, 4(2):123-133.

25. Araujo FG, Rosenberg LT, Remington JS: Experimental Toxoplasma gondii infection in mice: the role of the fifth component of complement. Proc Soc Exp Biol Med 1975, 149(3):800-804.

26. Wetsel RA, Fleischer DT, Haviland DL: Deficiency of the murine fifth complement component (C5). A 2-base pair gene deletion in a $5^{\prime}$-exon. J Biol Chem 1990, 265(5):2435-2440.

27. Smith RS, Zabaleta A, Kume T, Savinova OV, Kidson SH, Martin JE, Nishimura DY, Alward WL, Hogan BL, John SW: Haploinsufficiency of the transcription factors FOXC1 and FOXC2 results in aberrant ocular development. Hum Mol Genet 2000, 9(7):1021-1032.

28. Smith RZA, John SWM: Light microscopy. In Systematic Evaluation of the Mouse Eye: Anatomy, Pathology and Biomethods. Boca Raton, Florida: CRC Press; 2002

29. John SW, Smith RS, Savinova OV, Hawes NL, Chang B, Turnbull D, Davisson M, Roderick TH, Heckenlively JR: Essential iris atrophy, pigment dispersion, and glaucoma in DBA/2J mice. Invest Ophthalmol Vis Sci 1998, 39(6):951-962.

30. John SW, Hagaman JR, MacTaggart TE, Peng L, Smithes O: Intraocular pressure in inbred mouse strains. Invest Ophthalmol Vis Sci 1997, 38(1):249-253.

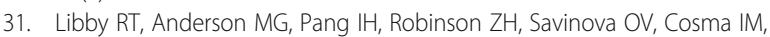
Snow A, Wilson LA, Smith RS, Clark AF, et al: Inherited glaucoma in DBA/2J mice: pertinent disease features for studying the neurodegeneration. Vis Neurosci 2005, 22(5):637-648

32. Libby RT, Li Y, Savinova OV, Barter J, Smith RS, Nickells RW, John SW: Susceptibility to neurodegeneration in a glaucoma is modified by Bax gene dosage. PLoS Genet 2005, 1(1):17-26.

33. Arumugam TV, Tang SC, Lathia JD, Cheng A, Mughal MR, Chigurupati S, Magnus T, Chan SL, Jo DG, Ouyang X, et al: Intravenous immunoglobulin
(IVIG) protects the brain against experimental stroke by preventing complement-mediated neuronal cell death. Proc Natl Acad Sci U S A 2007, 104(35):14104-14109.

34. Bellander BM, Singhrao SK, Ohlsson M, Mattsson P, Svensson M: Complement activation in the human brain after traumatic head injury. J Neurotrauma 2001, 18(12):1295-1311.

35. Pedersen ED, Loberg EM, Vege E, Daha MR, Maehlen J, Mollnes TE: In situ deposition of complement in human acute brain ischaemia. Scand Immunol 2009, 69(6):555-562.

36. Stasi K, Nagel D, Yang X, Wang RF, Ren L, Podos SM, Mittag T, Danias J: Complement component $1 \mathrm{Q}(\mathrm{C} 1 \mathrm{Q})$ upregulation in retina of murine, primate, and human glaucomatous eyes. Invest Ophthalmol Vis Sci 2006, 47(3):1024-1029.

37. Fuchs M, Scholz M, Sendelbeck A, Atorf J, Schlegel C, Enz R, Brandstatter $\mathrm{JH}$ : Rod photoreceptor ribbon synapses in DBA/2J mice show progressive age-related structural changes. PLoS One 2012 7(9):e44645.

38. Chenoweth DE, Hugli TE: Demonstration of specific C5a receptor on intact human polymorphonuclear leukocytes. Proc Natl Acad Sci U S A 1978, 75(8):3943-3947.

39. Gerard NP, Gerard C: The chemotactic receptor for human C5a anaphylatoxin. Nature 1991, 349(6310):614-617.

40. Hugli TE: The structural basis for anaphylatoxin and chemotactic functions of C3a, C4a, and C5a. Crit Rev Immunol 1981, 1(4):321-366.

41. Howell GR, Soto I, Zhu X, Ryan M, Macalinao DG, Sousa GL, Caddle LB, MacNicoll KH, Barbay JM, Porciatti $V$, et al: Radiation treatment inhibits monocyte entry into the optic nerve head and prevents neuronal damage in a mouse model of glaucoma. J Clin Invest 2012, 122(4):1246-1261.

42. Mukherjee P, Pasinetti GM: The role of complement anaphylatoxin C5a in neurodegeneration: implications in Alzheimer's disease. J Neuroimmunol 2000, 105(2):124-130.

43. Osaka H, McGinty A, Hoepken UE, Lu B, Gerard C, Pasinetti GM: Expression of $\mathrm{C} 5 \mathrm{a}$ receptor in mouse brain: role in signal transduction and neurodegeneration. Neuroscience 1999, 88(4):1073-1082.

44. Mukherjee P, Thomas S, Pasinetti GM: Complement anaphylatoxin C5a neuroprotects through regulation of glutamate receptor subunit 2 in vitro and in vivo. J Neuroinflammation 2008, 5:5

45. Howell GR, Walton DO, King BL, Libby RT, John SW: Datgan, a reusable software system for facile interrogation and visualization of complex transcription profiling data. BMC Genomics 2011, 12:429.

46. Kuehn MH, Kim CY, Ostojic J, Bellin M, Alward WL, Stone EM, Sakaguchi DS, Grozdanic SD, Kwon YH: Retinal synthesis and deposition of complement components induced by ocular hypertension. Exp Eye Res 2006, 83(3):620-628

47. Stahel PF, Flierl MA, Morgan BP, Persigehl I, Stoll C, Conrad C, Touban BM, Smith WR, Beauchamp K, Schmidt Ol, et al: Absence of the complement regulatory molecule CD59a leads to exacerbated neuropathology after traumatic brain injury in mice. J Neuroinflammation 2009, 6:2.

48. Ramaglia V, King RH, Nourallah M, Wolterman R, de Jonge R, Ramkema M, Vigar MA, van der Wetering S, Morgan BP, Troost D, et al: The membrane attack complex of the complement system is essential for rapid Wallerian degeneration. J Neurosci 2007, 27(29):7663-7672.

49. Stoltzner SE, Grenfell TJ, Mori C, Wisniewski KE, Wisniewski TM, Selkoe DJ, Lemere CA: Temporal accrual of complement proteins in amyloid plaques in Down's syndrome with Alzheimer's disease. Am J Pathol 2000, 156(2):489-499.

50. Ramaglia V, King RH, Morgan BP, Baas F: Deficiency of the complement regulator CD59a exacerbates Wallerian degeneration. Mol Immunol 2009, 46(8-9):1892-1896.

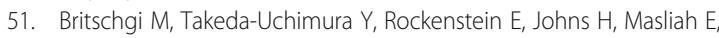
Wyss-Coray T: Deficiency of terminal complement pathway inhibitor promotes neuronal tau pathology and degeneration in mice. $J$ Neuroinflammation 2012, 9:220.

doi:10.1186/1742-2094-10-76

Cite this article as: Howell et al:: Deficiency of complement component 5 ameliorates glaucoma in DBA/2J mice. Journal of Neuroinflammation 2013 10:76. 